\title{
The challenge of new directions
}

Marcello D. Bronstein'

$I^{3}$ am very happy to become the Editor-in-Chief of our dear journal but, at the same time, I am very concerned with the responsibility of replacing the important people that preceded me since the journal started to be published by Waldemar Berardinelli. Some were professors who greatly influenced me towards becoming an Endocrinologist, such as Thales Martins, Clementino Fraga Filho, Luiz Carlos Lobo, Pedro Collet-Solberg, and João Gabriel Cordeiro. Others were references in their areas: the much-missed Armando de Aguiar Pupo, Antonio Roberto Chacra, Rui M. B. Maciel, Cláudio E. Kater, Edna T. Kimura, and Sérgio A. Dib. With the promise to increase the impact factor and the international recognition of our journal, I decided to request its name to be changed to "Archives of Endocrinology and Metabolism" (AE\&M), removing the term "Brazilian". I believe that this measure - which may seem as antipatriotic at first - aims at making Brazil even more visible in the international scientific community. In fact, I expect that, little by little, colleagues in Brazil and abroad give prestige to our journal by submitting high level articles. This will only be possible if AE\&M, by raising its impact factor, becomes attractive mainly to colleagues in universities that depend on their publications for their academic careers and qualification of their Disciplines.

I should remind you that "Clinical Endocrinology" is the official journal of the British Society for Endocrinology; the "Journal of Endocrinological Investigation" is the official journal of the Italian Society of Endocrinology; and the "Endocrine Journal", represents the Japan Endocrine Society. We can see that three of the most important societies of endocrinology have journals that do not show the names of their respective countries. However, the subtitle of the "AE\&M" will be the "Official Journal of the Brazilian Society of Endocrinology and Metabolism".

As English is the international language of science, the AE\&M will be published online only in English. However, the paper issues will show articles in Portuguese. As a matter of fact, I have noted that our journal have been publishing most of its articles in English.

For faster acceptance or rejection of submitted article, I increased the number of co-editors to 10 colleagues that are highly qualified in their sub-areas of specialty. The Brazilian Editorial Commission, as always, will be made up by experienced and productive colleagues in their respective areas. The International Editorial Commission will be made up by highly recognized professionals who have links in Brazil.

At this moment of my career I face this challenge as a very difficult one but, at the same time, a very fulfilling one. I hope that everybody in our scientific community collaborates with this venture and takes part in it, submitting articles and sending suggestion to improve our work. I count on you!

${ }^{1}$ Chief, Neuroendocrine Unit Division of Endocrinology and Metabolism

Hospital das Clínicas, University of São Paulo Medical School, São Paulo (HCFMUSP), SP, Brazil

Correspondence to Marcello D. Bronstein Rua Botucatu, 572 - conjunto 83 04023-062 - São Paulo, SP, Brazil

Received on Jan/28/2015 Accepted on Jan/28/2015 DOI: 10.1590/2359-3997000000002 